\title{
Constrained sustainable urban mobility: the possible contribution of research by design in two Palestinian cities
}

Kobe Boussauw ${ }^{1}$ \& Fabio Vanin ${ }^{2}$

${ }^{1}$ Cosmopolis Centre for Urban Research - Department of Geography, Vrije Universiteit Brussel, Pleinlaan 2, 1050 Brussels, Belgium, email: kobe.boussauw@vub.be, tel. +32 26293511

${ }^{2}$ Cosmopolis Centre for Urban Research - Department of Geography, Vrije Universiteit Brussel, Pleinlaan 2, 1050 Brussels, Belgium, email: fabio.vanin@vub.be, tel. +32 26293510

To be cited as:

Boussauw, K., \& Vanin, F. (2018). Constrained sustainable urban mobility: the possible contribution of research by design in two Palestinian cities. Urban Design International, doi: 10.1057/s41289-0180059-y

The project that was at the origin of the current paper was financially supported by the Cabinet of the Minister in charge of Mobility and Public Works of the Brussels Capital Region, Belgium. 


\begin{abstract}
In this paper we try to ascertain what the term 'sustainable urban mobility' can mean in the Palestinian society, which is strongly constrained in its development by a latent conflict. The article is situated in a tradition of phronetic planning research in which the authors take on the role of a participant observer, while the graphical products of the process (plans, views, sketches) are also considered an important data source and mediation tool. Throughout the process of research by design, we discuss the concepts of urban sustainability and livability in a conflictual context dominated by segregation and physical isolation. We do this by confronting supposedly orthodox conceptions from the literature, which is dominated by authors from the Global North, with the vision of students, professors and policy makers who live and work in a particular study area in Palestine. Then we define the possible contribution of a short term and constrained research by design process as an effective method in such a context, in order to both develop new knowledge, to produce tools for mediation and defend a vision for the future in a conflict situation. We conclude that, even if limited by specific constraints of time, data scarcity, access to sources, and problematic fieldwork conditions, research by design can serve as a platform for the development of contextsensitive and solution-oriented knowledge that transcends traditional, often paternalistic, ways of policy transfer.
\end{abstract}

Keywords: sustainable urban mobility; research by design; policy transfer; best practices; urban design; Palestine 


\section{Introduction}

In the current article, we assess the possible merits of a practical planning case in terms of intercultural exchange of expertise and in developing thorough insight in the opportunities for future development of the urban areas under scrutiny, viewed from the perspective of urban livability and sustainable urban mobility. We will do so through the lens of the concepts of policy transfer, best practice research, and research by design, while the cases discussed are two cities in the West Bank, Palestine.

Following Dolowitz \& Marsh (2000), policy transfer has recently become an important theme in the planning literature. At the same time, there is an ongoing debate about the importance of design (Kempenaar et al., 2016) and the use of best practices (Bulkeley, 2006) in developing knowledge. Some authors view the last two topics as part of the method of 'research by design' (Klaasen, 2007; Van den Akker et al, 2006; Bowring, 1997), in which the design process itself is considered an instrument for developing knowledge about the possible future of the targeted area. Although the aforementioned literature primarily takes a theoretical stance, Flyvbjerg (2004) makes a stand for what he calls phronetic planning research, which through the reporting of a detailed narrative of a real planning process should lead to a thorough understanding of the diverse impacts on the process's outcome.

Inspired by the abovementioned considerations, while faced with a highly complex case in terms of urban and transport development, in the current paper we employ a research by design endeavour in two cities in the West Bank, Palestine, to investigate the possible role of research by design in thinking about urban livability and sustainable mobility, and to provide more insight into the position of both design and best practice research within the broad spectrum of forms of policy transfer. In this manner, the present article aims to contribute to the debate on policy transfer in the fields of urban planning, mobility planning, and urban design. Rather than an extension of existing topical theories, we aim to respond to the demand for more contextualized short term micro research, and to contribute to an evolving volume of existing phronetic planning research.

The unique context of our own cases, situated in a tense socio-spatial environment that extends from the Palestinian hills to the Israeli urbanized and industrialized coastal plain, renders parallel influences from the so-called Global North and Global South. In the research by design exercise on urban mobility in two Palestinian cities under scrutiny, both Palestinian and Belgian students and professors were involved, while the authors position themselves as participating observers. Although the described projects served first and foremost educational purposes, we believe that they also yield important insights into mutual policy transfer, into the context sensitivity of concepts such as 
sustainable mobility and urban livability, and into the impact of a relatively isolated and poor existence that is enforced by a neighbouring prosperous nation.

The goal of the paper is multiple: we want to highlight the purpose of gaining insight in the meaning and the use of research by design as a method of policy transfer under precarious conditions, and we aim for knowledge production about the specific conditions of urban and transport planning in Palestinian cities. Research by design is therefore not the research method used to arrive at the conclusions of the current paper, but is part of the process under scrutiny. Based on the foregoing considerations, and based on our view of a number of specific issues in the two cities at hand, we formulate the research questions as follows:

- To what extent do limited personal freedom and militarily enforced restrictions in terms of urban development influence visions of the future of the Palestinian cities?

- To what extent are stakeholders in specific conflictual contexts of the Global South, such as Palestine, acquainted with and critical towards planning concepts that are known as progressive in the Global North, such as discouraging car use in city centres?

- Could the use of best practices be viewed as an adequate tool for organizing policy transfers between similar cases, albeit in different contexts?

In the remainder of this paper we descend from a theoretical stance towards a practical case. We start from a theoretical literature review, after which the study area and its specific issues is introduced, a section that is followed by a discussion of the analysis and outcomes. Practically, the article is structured as follows. Section 2 provides a concise literature review of policy transfer, research by design, and best practice research, concepts that inspired the research questions. Section 3 then summarizes the impact of the Israeli-Palestinian conflict in terms of urban development and transport on the West Bank. Section 4 discusses the perception of issues of sustainable mobility and urban livability in Palestine. Section 5 introduces the case, while in section 6 the progress and findings of the research by design are discussed through the use of fragments that have been written by the actors involved, as they were published in the final report of the research by design process. Finally, in section 7 the three research questions are responded to, while the course of the process is summarized in section 8.

\section{Policy transfer, research by design, and best practice research}

In their seminal paper, Dolowitz \& Marsh (2000) developed a much quoted theoretical framework to classify and evaluate practices of policy transfer. They motivate the need for such a framework from the worldwide growth of policy transfers, which are driven increasingly by international organizations such as the OECD, G-7, IMF or the UN and its many agencies. Dolowitz \& Marsh (2000) 
attach great importance to detecting patronizing sorts of policy transfer, for which they propose a spectrum which is situated between 'learning' and 'imposed transfer'. The one extreme of the spectrum is about policy transfer that is spontaneously identified by the receiving party as a solution to a problem. On the other hand, imposed transfers are effected within power relationships in which the centre of gravity of power is in the party that is transferring the policy. The existence of imposed policy transfers seems not self-evident in a post-colonial world, but occurs in situations where countries (or regions) are in a dependent position relative to, for example, international organizations. Policy transfers that are or were occurring in Eastern European countries within the framework of the accession process to the EU may serve as an example (Schimmelfennig \& Sedelmeier, 2004).

Based on a limited number of cases, Marsden \& Stead (2011) verify the meaning of the framework of Dolowitz \& Marsh (2000) in terms of transport policy. Healey (2013) discusses the concept of policy transfer with respect to spatial planning practice. Unlike the authors cited above, she emphasizes the role of the colonial past and postcolonial power relations, which indeed have left a significant mark on the urban layout of many cities in former colonial territories. Although Healey (2013) recognizes that a lot of research has been done into the social dynamics that policy transfers entail, she also indicates that specifically in the field of urban and spatial planning there is a need for more empirical research on what she calls micro-practices.

Bulkeley (2006) stands up for developing new insights through case study research, which she sees as a method for permanent recalibration of planning issues. Flyvbjerg (2004) argues for what he calls phronetic planning research, which through the reporting of a detailed narrative of a real planning process should lead to an understanding of the impact of power relations on the outcome of the planning process, and of the impact on the various stakeholders. Finally, we also want to emphasize the importance of the position of the researcher in the analysis of policy transfer processes in the field of spatial planning. Although in research practice it is rather common that researchers are not part of the object under study, Healey (2013) not coincidentally refers to actor-network theories, where the research object is supposed to be socially constructed, and the researcher (the research subject) is an observing participant (De Jong \& Edelenbos, 2007; Boelens, 2010; Gehl, 2013). Planning as well as research by design are in fact pre-eminent realms where there is considerable temptation for the researcher to engage in practice and process, rather than only studying these (Balducci and Bertolini, 2007). When it comes to design, urbanists, taking from the fields of architecture, planning as well as sociology and especially anthropology, have played the role of the researcher-observerdesigner-mediator (Gehl, 2013; Secchi 2007).

When scoping towards urban planning practice, these considerations lead us to the concept of research by design. Today, research by design or design-based research is a widely diffused applied 
methodology in a variety of contexts. Nevertheless, the debate about its exact definition is ongoing and largely depends on casual accents on certain aspects (Van den Akker, 2006). We can state that research by design is a flexible methodology that emphasises urban design and spatial visioning as a process, giving importance to educational practices where the collaboration among researchers and practitioners from different disciplines and the employment of context-sensitive design principles and theories is fundamental (Wang and Hannafin, 2005). In that framework, shared analytical tools and design results themselves are used as means to produce knowledge and to critically enquire a specific issue or case study. Therefore, on the one hand research by design aims to better understand the multiple aspects of the context, and on the other hand to outline a possible future development perspective that is policy supporting in nature.

However, it is not easy to identify the success factors of a research by design experience. The complexity of the area and the project, the historical roots and socio-cultural aspects, the multitude of actors involved or to be involved, and the characteristics of the physical environment are just some of the context-dependent variables which are decisive for the quality of the result of a research by design exercise. Those elements are often difficult to grasp due to factors such as the lack of knowledge and data, limited time and resources, or difficult access of the locations under scrutiny. Nevertheless, even short experiences, mostly conducted within an educational programme by students, can be extremely valuable if some key conditions are taken in account. Firstly, especially in case of international teams, researchers need to interact with local experts and actors in order to integrate a variety of research methods and approaches from both qualitative and quantitative paradigms, trying to adapt and integrate methods and theories to the context. Thus, depending on the needs, the design process through which results are generated has to be open and set where the research is conducted (Wang \& Hannafin, 2005), grounding in both theory and the real-world context.

\section{Context: the Israeli-Palestinian conflict in terms of spatial development}

Besides its historical roots, the Israeli-Palestinian conflict gained momentum in 1948 when the British mandate of Palestine ceased to exist, and Israel was declared an independent state. The Suez Crisis (1956) and the Six Day War (1967) reinforced the polarization, and led to a permanent occupation of both the West Bank and the Gaza Strip by Israel. This occupation has since been consolidated by the construction of Jewish settlements and infrastructure in both Palestinian territories, which are otherwise physically separated. After the so-called first intifada (Palestinian uprising between 1987 and 1990), in 1993 the Oslo Accords were agreed upon, which prescribed the creation of a Palestinian Authority, and offered the prospect of a Palestinian State (Newman, 1999). 
In reality, however, additional Israeli settlements have been built in the West Bank ever since, and the Israeli military government controls the spatial development of Palestine on the basis of a geographical hierarchical zoning system (Abdulhadi, 1990). In that system, densely populated areas are usually classified as area A, where the Palestinian Authority basically enjoys, or should enjoy, sovereignty. Area B refers to the areas under the joint administration of both the Israeli and the Palestinian government, while area $\mathrm{C}$ refers to the Palestinian areas controlled by the Israeli government that are inhabited by both Jewish settlers and Palestinian residents (Bhavnani et al., 2011) (Fig. 1).

The conflict has untold impact on the urban and regional development of the West Bank (Weizman, 2007). Areas $B$ and $C$ are as good as useless as construction land, causing urban expansion largely limited to densification of the existing cities. Moreover, transport facilities are to a large extent restricted by the conflict. In addition, many natural resources, including farmland and potential mining sites in area $C$, which comprises over $60 \%$ of the West Bank, are virtually inaccessible to the Palestinian economy. We discuss the limitations that apply within the categories of urban development and transport in the following paragraphs.

\subsection{Urban development}

De facto Palestinian urban expansion opportunities are limited to the tightly demarcated areas A, which comprise the larger agglomerations such as Nablus and Ramallah-Al-Bireh-Beitunia (which we will abbreviate as 'Ramallah' from now on). Nevertheless, the cities are growing through internal population increases of more than $2.5 \%$ per year, and by rural exodus, including Palestinian residents leaving area $\mathrm{C}$. The area of Ramallah also underwent very rapid, massive transformations, with the move of numerous organizations from Jerusalem after the second intifada (2000-2005) which turned its three municipalities in a short time into a new urban agglomeration (AbuSada \& Thawaba, 2011). Therefore, Palestinian urban development is very compact, while the urban landscape is dominated by apartment blocks whose ground floor is often used as a shop, workshop or office.

The very tight development prospects of the Palestinian cities stand in stark contrast to the continuous building of Jewish settlements in area C. While these settlements are illegal for international law, in most cases they enjoy support and protection by the Israeli state, even if three quarters of the recently added Jewish settlements do not have a valid building permit. Even if the construction of settlements in area $\mathrm{C}$ is not communicated as official Israeli policy, yet this residential expansion is in fact part of a colonization strategy that makes progress towards a two-state solution slowly but surely impossible. The Jewish population in area C increased in the period 1972-2015 from about 1,000 to 389,000 , while the Palestinian population in the area - depending on the source - is estimated at 150,000 to 300,000 . 
An exceptional case is represented by Rawabi, a Palestinian 'new town' under construction since 2010, designed for 25,000 to 40,000 capita (Khalidi \& Samour, 2011): it has some similarities with Israeli settlements but it is largely located in area A, and shall comply with the Israeli rules regarding accessibility and water supply.

\subsection{Transport}

Jewish settlements in area C are served by an Israeli network of roads, motorways and bus lines, which are embedded in corridors that are also part of area $C$, and only exceptionally traverse area $B$ or A. These transport routes are under Israeli military control, but most can in principle be used by Palestinian cars and buses. Nevertheless, Palestinians living in the West Bank are severely hampered in their movement (Eklund \& El-Atrash, 2012).

International travellers from the West Bank must always pass through Israeli border controls, whether they use the Tel Aviv airport, or travel overland to Jordan. Palestinians generally cannot use the Tel Aviv airport, and have to travel overland to Amman in order to reach the nearest airport accessible to them.

Cars and buses that are registered with the Palestinian Authority, have no access to Israel, and may use Israeli roads in the West Bank only under certain conditions. Important parts of the Israeli roads in the West Bank are physically separated from the underlying road network that serves the Palestinian villages. In many cases, connecting roads between Palestinian villages do not branch to Israeli highways, that deliberately cross local roads through bridges or tunnels, in that way preventing local road access (Ahmad, 2015; Weizman, 2007). Strips of land along Israeli roads are systematically expropriated for security reasons. In some cases, there is a parallel system in which a state-of-the-art road is only accessible to vehicles with Israeli licenses, while a nearby Palestinian road, generally in worse condition, offers the same connection to vehicles with Palestinian licences. Although historically a railway network served the cities of Nablus, Al-Bireh, and Jenin, today the West Bank's railways are entirely dismantled.

Another major obstacle to the movement of Palestinians are the checkpoints and the occasional roadblocks. The West Bank has dozens of permanent Israeli checkpoints (Tawil-Souri, 2011; Doumani, 2004), as many again flying checkpoints, and permanent and non-permanent roadblocks, which restrict the mobility of Palestinians in an unpredictable way (El-Atrash et al., 2008).

\section{Sustainable mobility and urban livability in Palestine}

Today, we can argue that there is such thing as a paradigm of sustainable mobility, which in the Global North forms the basis of most local mobility plans, and is an important component in spatial 
development plans (Boussauw \& Vanoutrive, 2017). This paradigm of sustainable mobility, that was identified by Banister (2008), focuses on technological innovation, substitution of trips, modal shift and reduction of distances between potential destinations by compact spatial development. Keblowksi \& Bassens (2017) see this paradigm evolve towards 'critical mobility', to which social justice, rather than environment, is central.

Both approaches (sustainable and critical mobility) have in common that they must be situated in the context of developed economies. When the growth of the transport system bumps up against its own boundaries, and more mobility no longer necessarily equals more wealth or well-being, social support grows to pursue progress in terms of improved environmental quality and social justice. In the context of more precarious societies, such as developing countries or (post) conflict areas, however, the perspective changes. The severity of social problems such as unemployment, political and financial instability, lack of education and health, or general security, largely overshadows concerns with regards to sustainable or critical mobility. Nevertheless, mobility-related social issues have become ever more problematic in the Global South. Road safety issues, noise, dust and air quality problems in city centres, and the disproportionate consumption of public space by private vehicles, have now virtually become global problems (Pojani \& Stead, 2016).

Moreover, the paradigm of sustainable mobility has also found its way to the Global South. Worldwide information networks, diaspora contacts, the explosive growth of international mobility and academic exchange today guarantee a massive dissemination of knowledge and consciousness that could even not be imagined in the recent past (Benson \& Jordan, 2011). This is particularly the case in the Holy Land, where the difference between Israel and Palestine is often only a few meters away. Thanks to their studies abroad and their international contacts, policy makers and academics in Palestine are well aware of the paradigm of sustainable mobility, of best practices in the field of transport policy and urban planning, and the quality of their teaching pursues a high level. The weak economy and the uncertainty associated with the unstable political situation, however, make transport planning in Palestine first and foremost follow the path of what Keblowski \& Bassens (2017) call traditional or orthodox thinking of mobility. Mobility is seen first and foremost as a way to facilitate economic growth. Building roads, separating pedestrians and cars, and the provision of parking spaces in the city centre are standard ingredients of current policy (Abu-Eisheh \& Al-Sahili, 2006). Public transport is largely left to the private sector, resulting in an organic system of shared taxis in which the role of the authorities is limited to the sale of licenses and the exploitation of the terminals. Public and recreational space is scarce, the one for safe walking and cycling, for children, elderly or disabled people is either absent or very cramped.

Frustrations caused by the politically constrained freedom of movement, make the Palestinians dream of cars, motorways, high-speed railway lines, and an own airport. An interesting example of 
how the Palestinian elite intertwines such a vision with ideas on sustainable mobility is a movie that is issued by the Ministry of Planning as a means to initiate the debate on the development of a longterm vision for the Palestinian State. Although the movie brings into focus motorways, an airport and a seaport, it is also about trains, subways, buses and bicycles, and about public space and renewable energy (Fig. 2). In this message, the need to see transport as an economic development factor and the desire to present Palestine as a progressive and responsible state, come together (NSP, 2013). Despite the fact that the images show a rather generic urban development, the suggestions seem to be strictly based on punctual needs and tight to pressing societal challenges.

\section{Case study and method}

Our analysis is based on the results of two research by design workshops on urban mobility and urban livability in the Palestinian cities of Nablus and Ramallah. Nablus and Ramallah are two of the three major urban agglomerations on the West Bank (apart from Hebron). Both cities are characterized by a problem of rapid urbanization in combination with mobility and urban livability issues. In the project, Belgian master students in the urban design and spatial planning programmes of the Vrije Universiteit Brussel (VUB) and Antwerp University cooperated with Palestinian students in transport and urban planning at An-Najah University in Nablus.

The project included two weeks of intensive cooperation in the Centre for Urban and Regional Planning at An-Najah University, combing field visits, studio work, interviews and conversations with local experts. Relying on the theories discussed earlier, we view the research by design exercise as a source of information, which teaches how vision elements, consolidated models and examples from different contexts interact with each other and then crystallize into an urban design proposal. Research and design activities were largely organized around two study areas and themes. In Nablus, the urban east-west axis was under scrutiny, with the intention of organizing public transport more efficiently while reducing traffic inconvenience to residents and enhancing the quality of public space. In Ramallah, the activities were geared towards the central market area, where pedestrians are largely representative of the urban dynamics, although cars dominate the streets. Logically, public space, traffic circulation and pedestrianization were to become key concepts in the design. In what follows, we report on how ideas and concepts related to sustainable or critical mobility have permeated in the design proposals in both cities, paying particular attention to the adaptation of such ideas and concepts to the specific context.

\subsection{Situating the east-west corridor in Nablus}


Given its location in a valley, Nablus has a long and compressed, east-west oriented structure, which is carried by only one wide transport corridor. Since this corridor is the only connection between the eastern, the western, and the central part of the city, traffic is usually very busy. The western end of the corridor is formed by a terminal for minibuses or shared taxis, which connects the western surrounding villages to the city. The municipality has a plan to build a similar eastern terminal at the easternmost end of the corridor (Fig. 3). Both shared taxis, city taxis and private vehicles go through the city centre, where today several stations for shared taxis are present. Central along the corridor is the city centre, including the old market, a commercial core with a shopping mall, and a parking building (ARIJ, 2014). The following quote from the final report illustrates in a clear way how the geography of Nablus relates to the way the city operates today:

"As a result of the intense economic and service activities in Nablus City, it has become a destination for large numbers of people who travel to the city every day. This has resulted in a large number of vehicles entering the city daily, which causes increasing traffic congestion on the major roads, especially along the main east-west corridor across the valley. Thus, Nablus suffers from various transport problems, including traffic congestion, public transport terminals located inside the CBD, narrow streets, unavailability of proper public transport services, a high percentage of private vehicles, parking problems and excessive pollution in the CBD and some residential areas." (Vanin \& Boussauw, 2017, p. 39).

\subsection{Situating the central squares in Ramallah}

The agglomeration of Ramallah-Al-Bireh-Beitunia has grown rapidly, while the road network was hardly adapted to the associated increase of demand for transport. The centre of Ramallah, which borders the municipality of Al-Bireh (ARIJ, 2012), consists of two roundabouts that are interconnected within short distance and are centrally located in the commercial heart of the city (Fig. 4). Almost all traffic flows in the centre come together on these roundabouts. At the same time, major pedestrian flows are present too. There are no convenient bypass roads that are sufficiently attractive to possibly divert some of the traffic. Many sidewalks in the centre are separated from the roads with fences, but in reality pedestrians are walking in-between the vehicles. Near the centre there is a terminal for shared taxis, which is located in a sort of parking building. The following quote illustrates how local experts look upon the problem of urbanization and transport in Ramallah: "The recent increase in population and economic activity has resulted in the considerable growth of vehicular trips in an area that was already congested. To cope with this, the municipalities of Ramallah and Al-Bireh have undertaken several road rehabilitations and traffic improvements related to circulation, parking and public transport during the last few years. Despite that, traffic conditions, in general, have not improved much." (Vanin \& Boussauw, 2017, p. 72). 


\section{Process and results}

The research by design process was divided into three phases. Phase 1 included an exploratory spatial analysis of the study area and the development of a problem statement, and took place during the first week in Palestine. Phase 2 covered the period between the two workshops on site, during which students had to gather background information on the study area, to collect relevant best practices from which they could draw inspiration for their design and to further critically reflect on the process. Both the Belgian and Palestinian students worked from their own countries keeping regular contact. Finally, phase 3 included the actual design, which was developed during the second week in Nablus. Each of both study areas was repeatedly scrutinized by two working groups, which proceeded independently. In the next sections, we provide our own interpretation of the course and the outcome of the process, on the one hand drawing from our own experiences as a participant observer, and on the other hand relying on the final report of the workshops in which all participating actors, both students and tutors with various backgrounds, concisely reported on their experiences. In addition, we supplement our summary with quotes from the concerned report.

\subsection{East-west corridor in Nablus}

During the first phase, the teams took an analytical stance. Spatial problems were identified and mapped, existing flows of private vehicles, taxis, and pedestrians were quantified, the quality of sidewalks and crosswalks was reviewed, and the available parking spaces were counted. Their approach was rather detailed and operational. Potential obstacles that could impede the flow of fast public transport were listed, including a possibly too narrow gabarit, probable conflicts with car traffic, and the current congestion. The teams also attempted to identify the actors involved in the planning process for this area. The reported results of phase 1 highlighted in particular the numerous conflict points between pedestrians and motor vehicles, the through traffic that crosses the city centre causing considerable congestion, and the particularly bad layout of the roads.

In a second phase, a TW-OS analysis (grouping threats and weaknesses on the one hand, opportunities and strengths on the other) of the parking system produced a strong car-oriented vision: the high presence of parking space right in the city centre was described as of potential, and the presence of vacant lots was considered an opportunity for creating additional parking spaces. Weaknesses and threats appeared to be confined to an alleged lack of parking near major destinations, as well as the presence of congestion. Frequently recurring formulations of weaknesses or threats sounded as follows: "congested streets, risk of malfunction through traffic congestion", "insufficient lane width for buses in narrow streets", "disappearing parking lots", "conflict between 
transportation modes", "there is a lot of conflict points between the pedestrians and vehicles", "one of the biggest problems is double illegal parking on the street", "this section has real parking problems" (Vanin \& Boussauw, 2017, pp. 44-45).

A TW-OS analysis was also made on the connection between the western and the planned eastern terminal (Fig. 5). The ability to prevent through traffic by shared taxis was seen as an opportunity, while the possible future need to change buses or taxis was perceived as a threat (Fig. 6). The analysis was followed by a reflection in which the parking problem was linked to the development of a bus rapid transit system (BRT), partially discouraging car use in the city through the introduction of a more expensive parking fee scheme near the centre and a short-term parking regulation inside it, and a park-and-ride system with decentralized car parks linked to the rapid bus route.

Phase 2 was completed by collecting a number of best practices, good examples from other countries that could inspire design proposals for Nablus. Remarkably, one team only selected European examples, including a BRT system from France, taxi stands from the Netherlands and the UK, a Belgian short term parking system, and a Polish kiss-and-ride zone. The second team, however, consulted mainly projects in Africa and the Middle East, including Marrakech (Morocco), Amman (Jordan), Lagos (Nigeria) and Riyadh (Saudi Arabia).

A brief comparison between BRT and LRT (light rail transit), pushed one team to choose BRT in the short term, because of cost efficiency and shorter time required for implementation, with the possibility of turning the system into LRT in the long term. Inspired by an example from Paris, BRT buses were planned to be driven in the opposite direction of the general traffic flow, with the intent of discouraging (wrong-way driving) cars using the dedicated bus lanes.

In the third and final phase, which focused on a future solution in the form of an urban design proposal, a paradigm shift clearly appeared. The parking problem shifted to the background, and the design focused primarily on two items: firstly, the throughput of the BRT system, and secondly, adjusting public space to pedestrians and cyclists (Fig. 7). Bus stops were judiciously placed into locations near crowd-drawing activities in the city, and a design proposal of walkways between these destinations and the bus stops was developed. Furthermore, special attention was paid to the design of bus stops situated on the median strip of the corridors, giving access to the left side of the bus, and to safe and attractive pedestrian crossings (Fig. 8). The proposal for a phased development that eventually should result in an LRT system, was once again put in the spotlight. The following quotes from the final report are representative of the changing perspective:

"Moreover, the BRT project should be co-developed with projects to improve the walkability of the CBD, i.e., to create a walkable Nablus. To achieve that goal, public spaces and sidewalks must be adjusted and conceived for pedestrians. On-street parking must be restructured to provide space for a well-designed road layout for the BRT, pedestrians, bicycles and vehicles." 
"Finally, this project aims to stimulate a mind-switch on transport modes, giving priority to pedestrians to ensure a decongested, pleasant yet efficient walkable Nablus."

"The proposed pedestrian area stretches from around the main shopping centre to the old markets in the south and the bazar area on the eastern side of the city centre. The area offers spaces to street vendors to store and sell their goods from kiosks, located between green spaces and trees in order to create a lively and pleasant environment." (Vanin \& Boussauw, 2017, p. 53).

\subsection{Central squares in Ramallah}

Initially (during phase 1), great importance was attached to the position of the centre of Ramallah in Palestine and in the world, emphasizing the political symbolism of the place, which transcends the status of a traffic square and a physical heart of the commercial centre of the urban agglomeration. Moreover, the regional political context - the embedding of the urban agglomeration in Area $\mathrm{C}$, and the presence of Israeli settlements nearby hindering the expansion of both the built environment and transport infrastructure - was stressed.

The analysis paid attention to the density gradient, noticing that the densely populated area of Ramallah includes only a handful of closed building blocks, while density is rapidly declining as one moves away from the centre. Nonetheless, the largest part of the traffic in the metropolitan area traverses this densely populated area, as no convenient bypass roads are present. Furthermore, mapping parking spaces, the team emphasized the many derelict plots that are often temporarily in use as pay parking or even as a terminal for shared taxis (Fig. 9).

The acknowledged conflicting land use in the squares, especially in the Yasser Arafat-Square, is caused by through traffic, shopping pedestrians and passers-by, and political events continuously interfering with each other. The ambiguity of the fences that border the sidewalks with the intention to separate pedestrians from vehicle traffic was listed too: these seem to contribute to the safety of pedestrians, but allow at the same time cars to go faster. Moreover, those are systematically ignored by pedestrians. The following quotes may illustrate the analysis made: "the city is a passage for traffic through the centre, which creates a car-dominated environment"; "recently developed public space in the CBD is dominated by cars and it is designed to actually support them in the area"; "the large number of cars and shared taxis in the CBD limit outdoor activities and public events" (Vanin \& Boussauw, 2017, p. 93).

In the second phase, a distinction was made between the everyday use of public space, and the use during events and in the evenings, with the idea to implement a time-dependent car-free zone. References for the design of the squares were, among others, looked for in highly symbolic places where manifestations and large gatherings can happen (i.e. Schuman Square in Brussels near the headquarters of the European Union). Other best practices that were referred to, are the recently 
pedestrianized main boulevards in Brussels, and the continuously expanding pedestrian area of Strøget in Denmark.

Attention was called to the position of cars and shared taxis in the city, particularly in relation to the presence of pedestrians. Traffic circulation was brought into the picture, trying to direct through traffic, including shared taxis, further away from and around the centre. Given the urban fabric of narrow streets in which a ring structure must fit, this was designed as a one-way system. The inner centre was conceived as a pedestrianized area, although no statements were made yet about accessibility for residents, city taxis or buses. Furthermore, proposals were made for a cycling network which was meant to follow the relief contours as well as possible, and was combined with a bike sharing system.

In the final phase of the research by design, one proposal shifted from a temporary to a quasipermanent pedestrianized zone, and focused on enhancing the symbolic value and identity of the city centre (Fig. 10).

The proposed interventions are supported by the following quotes:

"The mobility issue needs to be solved at first: the proposed ring road has to be supported by public transport, implementing new bus lines. During the day taxis can stop at the edge of the city and high frequency busses can bring people to the $\mathrm{CBD}$, transformed into a pedestrian zone where bus lines do not cross or overlap in order to avoid congestion."

"Through solving the main traffic issues many car dominated spaces become available for other uses. Different functions could then be implemented supporting every scale, giving the necessary attention to existing activities (i.e. the market that already is a pedestrian zone)." (Vanin \& Boussauw, 2017, p. 75)

In the other proposal, the central squares were conceived as places for lingering and meeting, while cars and shared taxis were removed from this area and city buses were still able to traverse the pedestrian area. The shared taxi terminals were moved to the edge of the pedestrian zone, and parking spaces were transformed into display space for shops and market stalls. A bike sharing system was introduced diverting car traffic. Unlike the earlier version of the proposal, the bypass road was duplicated, with traffic running clockwise on the outer ring, and counter clockwise on the inner one. Radial connections link the inner to the outer ring, while some parts of these connections were reserved for city buses. Inside the inner ring, in principle no motorized traffic was authorized (Fig. 11).

When designing public space in the pedestrian area, the emphasis was put on expanding it and protecting open spaces where possible (i.e. the new terminal as a square with underground parking which is represented in Fig. 12) providing additional greenery with the intention to reduce urban heat island effects. Tourism was seen as a major opportunity, which should be supported by the 
design of the pedestrianized area. Finally, additional design proposals were made for the new bus terminals, shared taxis and organized pay parkings at the edge of the pedestrianized area. Some quotes from the final report may elucidate the design team's vision:

"Local practices and the livability of the area suffer from these negative mobility issues. The aim of the proposal is to reverse that trend by highlighting the landmarks of Ramallah and converting the car oriented city to one designed for pedestrians."

"Alternative transport modes allow to reduce the number of cars in the CBD: switching from private cars to buses or even to bikes (as far as this is allowed by the topography), using the proposed terminals outside the city centre and introducing new bus lines and bike stations."

"In the CBD cars will have dedicated roads only, while a new street design will provide more space for shopkeepers and pedestrians, preventing illegal parking while encouraging more appropriate and sustainable behaviours." (Vanin \& Boussauw, 2017, p. 93)

\section{Discussion}

In line with the research questions proposed in the introduction of this article, we identify three themes on which the workshops have provided new insights: (1) the straitjacket of the occupation, (2) transfer and construction of knowledge on urban mobility, and (3) the significance of the use of best practices.

\subsection{The straitjacket of the occupation}

Superficially viewed, the impact of the Israeli occupation to the planning and design exercise seems rather limited. In everyday life that takes place within the two cities, the conflict is hardly visible. However, this is very different for commuters, both employees and students living in villages outside the cities, and for those who commute between cities. Moreover, the occupation has created a very much closed social system, with severe negative consequences for economic and intellectual exchange.

In terms of urban design, the occupation urges for additional emphasis on the territorial aspect: urban development is associated with claims for habitat by the Palestinian people. Simultaneously, the Israeli military authority does not allow the city to expand outside area A, for which both cities considered have developed in an extremely compact manner. This very specific urban aspect of the occupation, obviously acknowledged by the students, had a strong impact on the design process. Compact development leads to more pronounced urban mobility issues, in which the lack of space to facilitate traffic comes to the fore, while high urban density ensures the efficiency of public transport solutions. 
However, the impact of the occupation comes much sharper into focus in the search for ways to build bypass roads and redirect part of the traffic around the centre. In such endeavours, the limitation of areas B and C are systematically encountered, where the - unlikely - permission from the Israeli military authorities is required before anything is to be built at all. Clearly, the impossibility of diverting traffic outside the compact urban fabric seriously hampers the development of any proper vision on urban mobility.

A final aspect is the development of the identity of a place. The occupation of Jerusalem has led to a need for public space with a symbolic and political significance, which is not compatible with the dominant presence of cars.

\subsection{Transfer and construction of knowledge on urban mobility}

Traditional one-way transfer of knowledge does clearly not apply to the four months research by design process described above. Despite the physical isolation in which most of the Palestinian population resides, Palestinian students, professors and policy makers are well familiar with concepts and implementation of sustainable and critical urban mobility. This has to do with the foreign track records of professors and a number of policy makers, but also with diaspora contacts, foreign-funded development projects, proximity to Israel, and the ubiquity of the Internet as an information channel. Therefore, the role of the research by design exercise discussed here consisted in rather providing a platform that facilitated combining different views and backgrounds, thus enabling bidirectional knowledge exchange and construction. Nevertheless, we saw a clear shift happening during the process, in which an initial orthodox approach to urban mobility makes way for a sustainable or even critical approach in which private vehicles are no longer central, but collective transport and public space for pedestrians, playing children, and even cyclists are. It is clear that this shifting emphasis has little to do with knowledge, but rather with a difference in approach between Palestinian and Belgian students who were forced to work on a shared vision. While the Palestinian perspective was strongly focused on economic development, the Belgian one was guided rather by the desire to increase environmental quality. Mutual learning was mainly related to reasoning from an alternative context, in which Belgian students learned to develop a vision within a context of significant economic constraints and limited freedom of movement, while Palestinian students learned to apply concepts of sustainability and redistribution to which they were already generally acquainted. Gathering existing data, collecting new information during fieldwork and using information provided by local and foreign experts on specific contextual matters and diffuse practices, surveys and mapping exercises - ranging from actor analysis to mapping traffic and behaviour in public space - have contributed both to exchanging as well as to building original knowledge. 


\subsection{The significance of the use of best practices}

The students were explicitly instructed to look for a number of best practices that could support their design proposals. This assignment was conceived by the various teams in different ways, in particular with regard to the research by design exercise that was situated in Nablus. The first team chose a BRT based solution, and quoted mainly European examples, while the second team mainly presented references from emerging economies, including the Middle East and Africa. The last team combined these with inspiration from Western Europe (e.g. buses in contraflow, like in Paris) and advocated a phased development which could possibly evolve towards electric buses and LRT. The teams that elaborated a project for Ramallah mostly cited examples from the Global North, but finally strongly adapted their proposals to the context by developing concepts strictly linked to local issues.

Following Bulkeley (2006), we think that the use of best practices is an important part of a research by design exercise to inform and support the proposed vision as well as to discuss and test existing references. However, it is important to integrate the (reference) projects in an open manner in an own, context-sensitive planning exercise.

\section{Conclusion}

This paper served different purposes. Firstly, we wanted to draw attention to the relevance of academic research by design activities under limited availability of time and in a context characterised by strong constraints, that can serve a combination of educational, scientific and policy supporting purposes. The educational and policy supporting aspects speak for themselves. The scientific use is located partly in the development of knowledge that evolves throughout the design process and in which the interpretation of best practices plays an important role, and also in the contribution to a phronetic line of research in the sense meant by Flyvbjerg (2004). The proposed visions for Ramallah and Nablus, even if limited and partial, are meant to be a tool for mediation and further discussion both at an international and local level.

Secondly, we wanted to evaluate to which extent the concept of policy and knowledge exchange could be applied in a framework in which perspectives from the Global North are faced with contextspecific perspectives and with views from the Global South. Despite the limitations, our experience has shown that under the condition of sufficient attention to the context of the place, traditional, one-way transfer is certainly not a desirable solution. The significant degree of global convergence in thinking on urban mobility and design, the open attitude of the actors involved, as well as the evident call for a site-specific approach due to the peculiarity of the Palestinian context, rendered the impossibility of applying top-down external concepts and models. 
Thirdly, the aim was to assess the impact of the specific situation of the occupation of the Palestinian territories on urban mobility planning. In summary we can say that the limited personal freedom and the militarily enforced restrictions on urban development greatly affect the vision of the desired future of the city, and that the degree to which urban mobility planning can be seen as a tool for making cities more sustainable and equitable is to a large extent dependent on the fulfilment of a number of economic and political preconditions.

\section{References}

Abdulhadi, R. S. (1990) 'Land use planning in the occupied palestinian territories', Journal of Palestine Studies, 19(4), pp. 46-63.

Abu-Eisheh, S., \& Al-Sahili, K. (2006). The framework for the development of a medium-term transportation program for an economy in transition: The Palestinian case. Presented at the The Palestinian Conference for Development and Reconstruction in the West Bank, Nablus: An-Najah University.

AbuSada, J. and Thawaba, S. (2011) 'Multi criteria analysis for locating sustainable suburban centers: A case study from Ramallah Governorate, Palestine', Cities, 28(5), pp. 381-393.

Ahmad, O. H. (2015) A Systems Approach to Understanding and Mitigating Barriers to Travel Accessibility and Well-being in the West Bank, Palestine - PhD thesis. Tempe, AZ: Arizona State University.

ARIJ (2012) Al Bireh City Profile. Jerusalem: The Applied Research Institute - Jerusalem. ARIJ (2014) Nablus City Profile. Jerusalem: The Applied Research Institute - Jerusalem. Balducci, A. and Bertolini, L. (2007) 'Reflecting on practice or reflecting with practice?', Planning Theory \& Practice, 8(4), pp. 532-555.

Banister, D. (2008) 'The sustainable mobility paradigm', Transport Policy, 15(2), pp. 73-80.

Benson, D. and Jordan, A. (2011) 'What have we learned from policy transfer research? Dolowitz and Marsh revisited', Political Studies Review, 9(3), pp. 366-378.

Bhavnani, R., Miodownik, D. and Choi, H. J. (2011) 'Three two tango: Territorial control and selective violence in Israel, the West Bank, and Gaza', Journal of Conflict Resolution, 55(1), pp. 133-158.

Boelens, L. (2010) 'Theorizing practice and practising theory: Outlines for an actor-relationalapproach in planning', Planning Theory, 9(1), pp. 28-62.

Boussauw, K. and Vanoutrive, T. (2017) 'Transport policy in Belgium: translating sustainability discourses into unsustainable outcomes', Transport Policy, 53, pp. 11-19.

Bowring, J. (1997). Research by design: the refereed studio. Landscape Review, 3(2), 54-55. 
Bulkeley, H. (2006) 'Sustainability: Learning from best practice?', Environment and Planning A, 38(6), pp. 1029-1044.

Dolowitz, D. and Marsh, D. (2000) 'Learning from abroad: The role of policy transfer in contemporary policy-making', Governance: An International Journal of Policy and Administration, 13(1), pp. 524.

Doumani, B. (2004). Scenes from daily life: The view from Nablus. Journal of Palestine Studies, 34(1), 37-50.

Eklund, L. and El-Atrash, A. (2012) 'Assessing mobility conditions in the West Bank territory using geographic information systems: The case of the Bethlehem-Ramallah route', The Arab World Geographer / Le Géographe du monde arabe, 15(2), pp. 127-138.

El-Atrash, A. A., Salem, H. S. and Isaac, J. E. (2008) 'Planning towards a sustainable land transportation system in a future Palestinian State', Journal of Nature Science and Sustainable Technology, 2(3), pp. 305-324.

Flyvbjerg, B. (2004) 'Phronetic planning research: theoretical and methodological reflections', Planning Theory \& Practice, 5(3), pp. 283-306.

Gehl, J. and Svarre, B. (2013) How to Study Public Life. Washington, DC: Island Press.

Healey, P. (2013) 'Circuits of knowledge and techniques: the transnational flow of planning ideas and practices', International Journal of Urban and Regional Research, 37(5), pp. 1510-1526.

De Jong, M. and Edelenbos, J. (2007) 'An insider's look into policy transfer in transnational expert networks', European Planning Studies, 15(5), pp. 687-706.

Keblowski, W. and Bassens, D. (2017) 'All transport problems are essentially mathematical': The uneven resonance of academic transport and mobility knowledge in Brussels, Urban Geography, doi 10.1080/02723638.2017.1336320 (in press), pp. 1-25.

Kempenaar, A., Westerink, J., van Lierop, M., Brinkhuijsen, M., \& van den Brink, A. (2016). “Design makes you understand": Mapping the contributions of designing to regional planning and development. Landscape and Urban Planning, (149), 20-30.

Khalidi, R. and Samour, S. (2011) 'Neoliberalism as liberation: The statehood program and the remaking of the Palestinian national movement', Journal of Palestine Studies, 40(2), pp. 6-25.

Klaasen, I. T. (2007) 'A scientific approach to urban and regional design: research by design', Journal of Design Research, 5(4), pp. 470-489.

Marsden, G. and Stead, D. (2011) 'Policy transfer and learning in the field of transport: A review of concepts and evidence', Transport Policy, 18(3), pp. 492-500.

Newman, D. (1999) 'Real spaces, symbolic spaces: Interrelated notions of territory in the Arab-Israeli conflict', in Diehl, P. F. (ed.) A Road Map to War: Territorial Dimensions of International Conflict. Nashville, TN: Vanderbilt University Press. 
NSP (2013) National Spatial Plan: Turning Challenges into Opportunities. Ramallah: National Spatial Plan Administration.

Pojani, D. and Stead, D. (2016) 'The urban transport crisis in emerging economies: An introduction', in Pojani, D. and Stead, D. (eds) The Urban Transport Crisis in Emerging Economies. Cham: Springer.

Schimmelfennig, F. and Sedelmeier, U. (2004) 'Governance by conditionality: EU rule transfer to the candidate countries of Central and Eastern Europe', Journal of European Public Policy, 11(4), pp. 661-679.

Secchi, B. (2007) Prima lezione di Urbanistica. Rome: Laterza.

Tawil-Souri, H. (2011). Qalandia Checkpoint as Space and Nonplace. Space and Culture, 14(1), 4-26.

Van den Akker, J., Gravemeiger, K., McKenney, S., \& Nieveen, N. (2006). Introducing Educational Design Research. In Van den Akker, J., Gravemeiger, K., McKenney, S., \& Nieveen, N. (Eds.), Educational design research. (pp. 1-8). London: Routledge.

Vanin, F., \& Boussauw, K. (Eds.). (2017). Transforming Mobility: Collective Transport and Spaces in Nablus and Ramallah. Brussels: VUB / ULB.

Wang, F. and Hannafin, M. J. (2005) 'Design-based research and technology-enhanced learning environments', Educational Technology Research and Development, 53(4), pp. 5-23.

Weizman, E. (2007). Hollow Land: Israel's Architecture of Occupation. London - New York: Verso. 


\section{Figures}

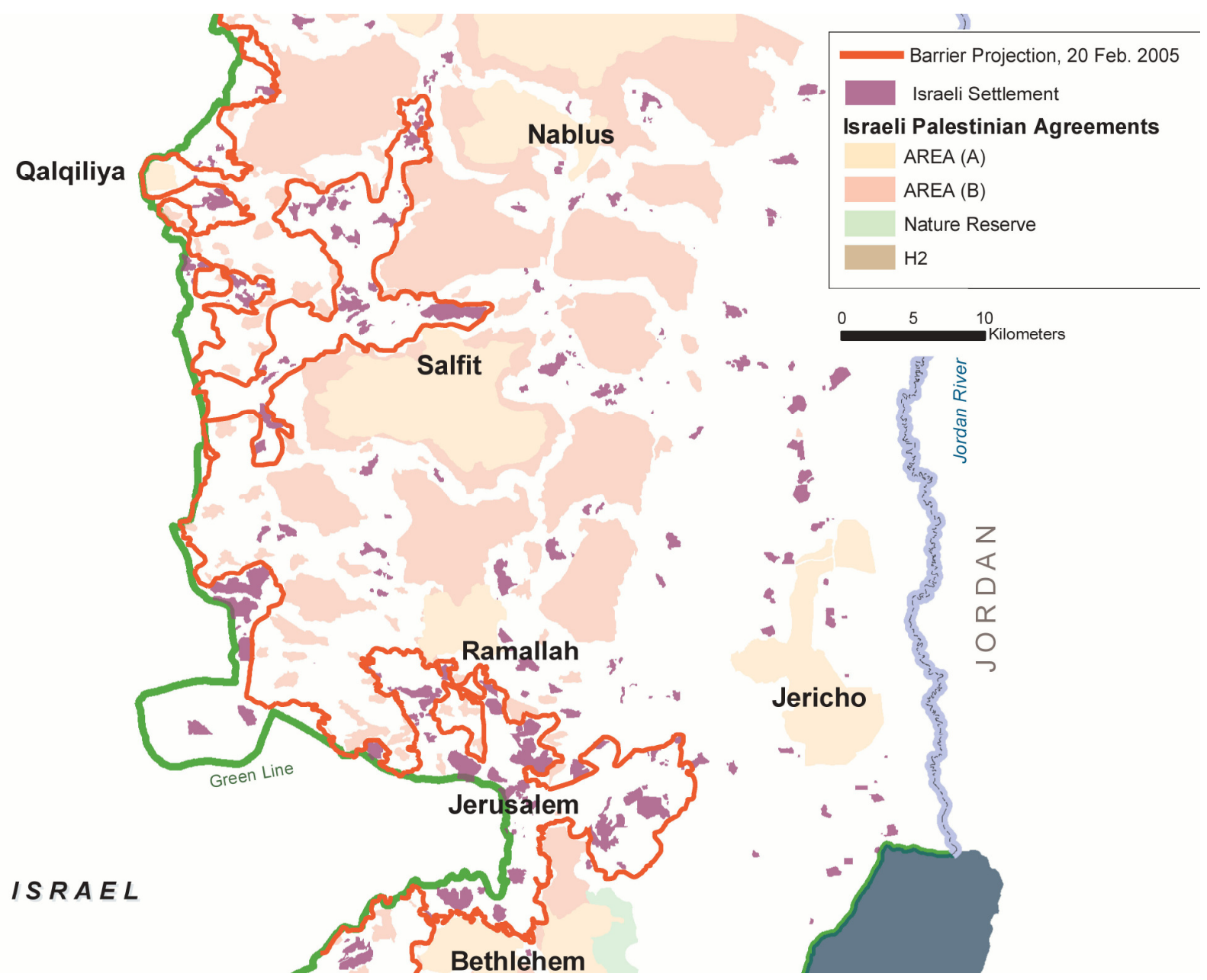

Fig. 1. The A-B-C zoning system in the central West Bank. Adapted from

https://upload.wikimedia.org/wikipedia/commons/5/5e/Oslo_Areas_and_barrier_projection_2005.p ng (licenced under Creative Commons) 


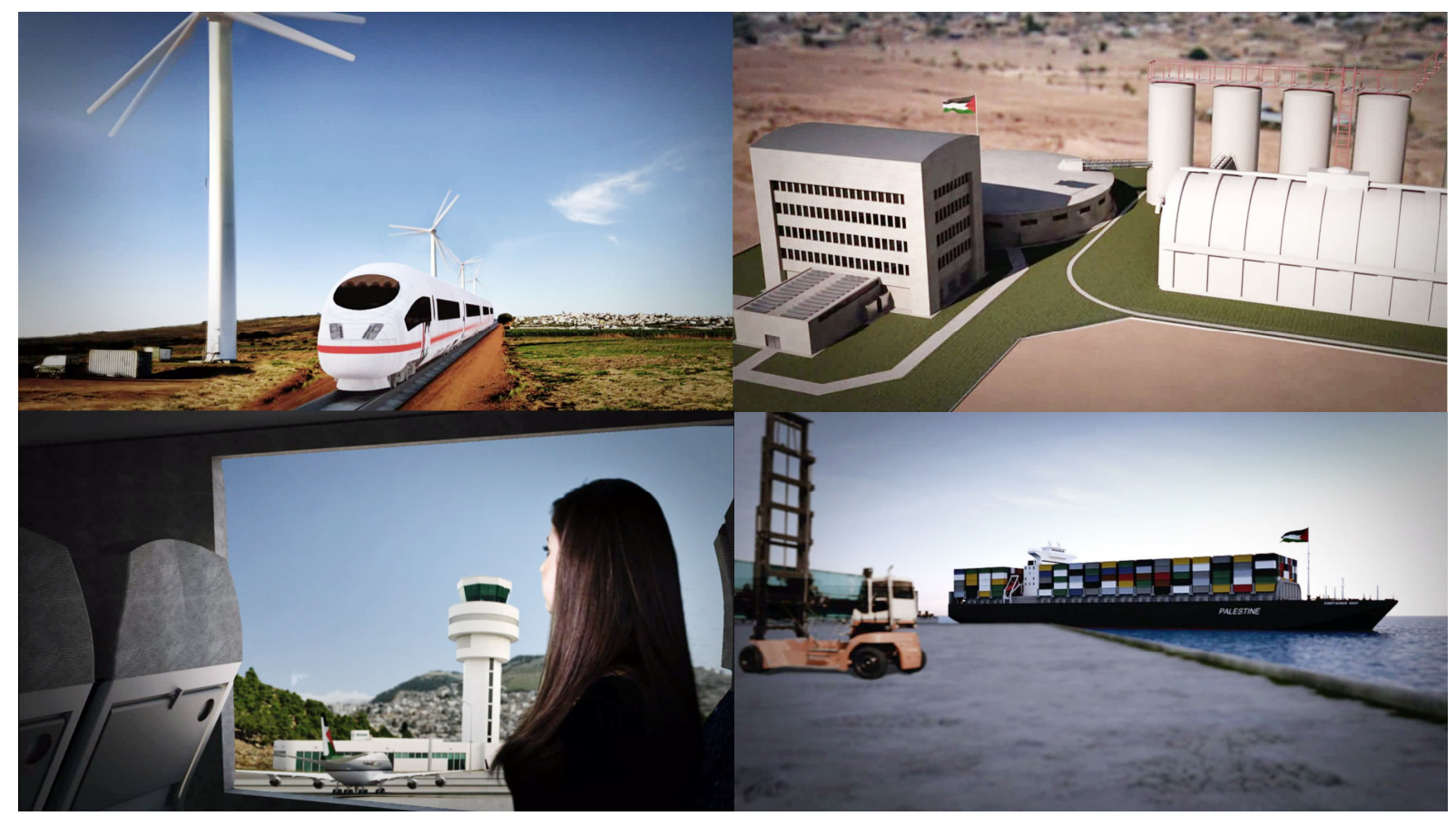

Fig. 2. Four scenes from the movie issued by the National Spatial Plan Office

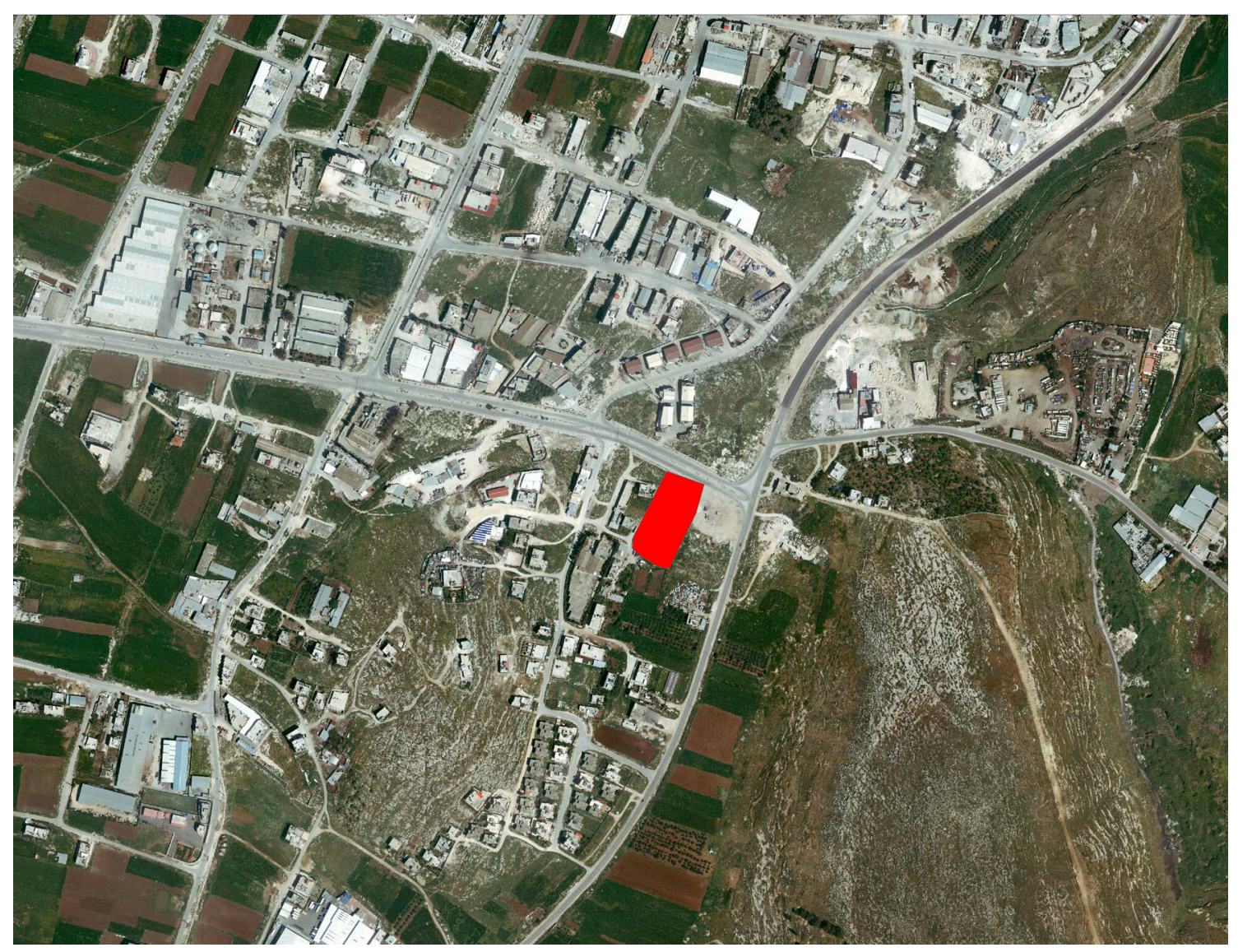

Fig. 3. Location of the new eastern terminal of Nablus 


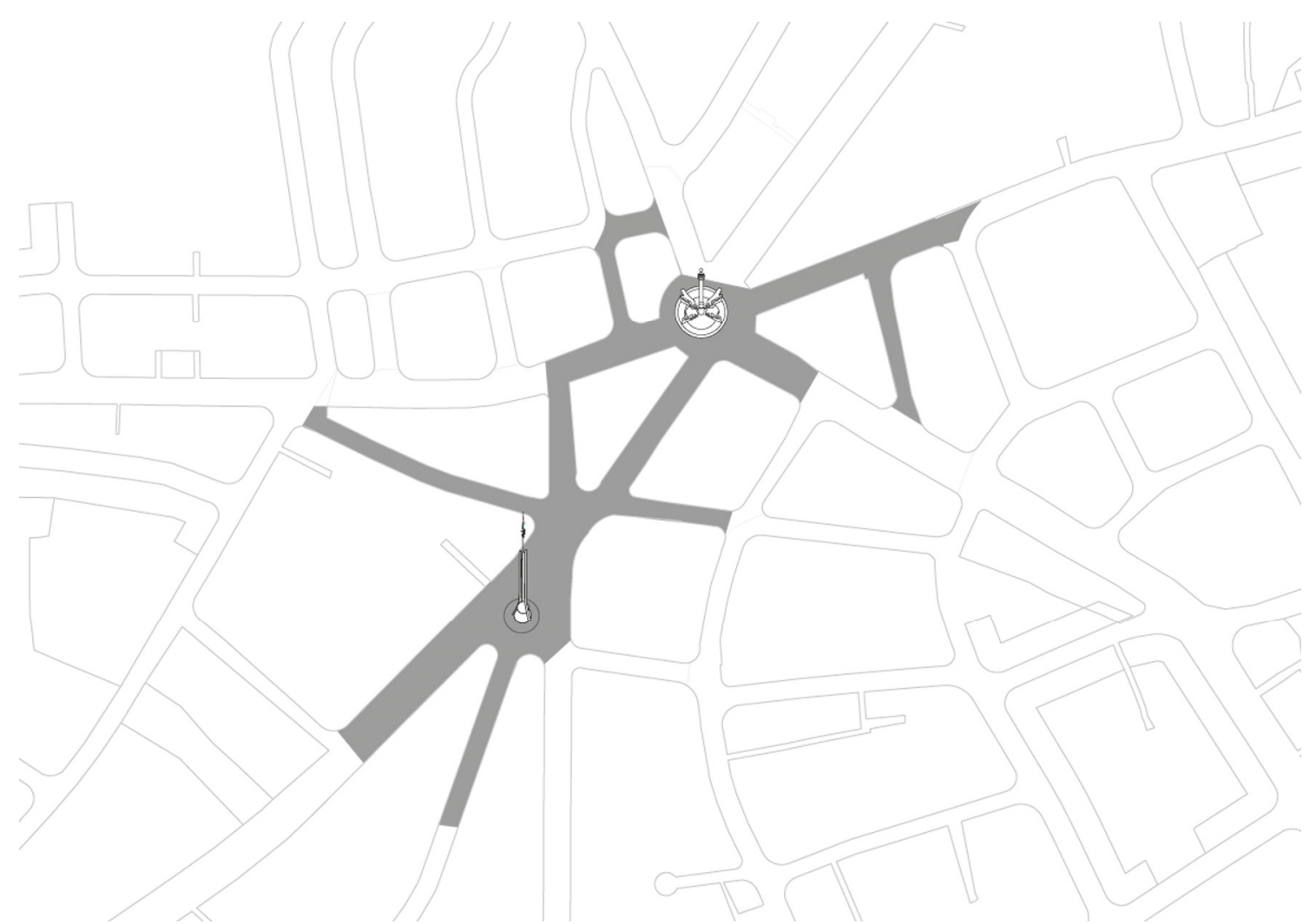

Fig. 4. Location of the two main squares-roundabouts in the CBD of Ramallah (Arafat square in the north and Al Manarah square in the south)

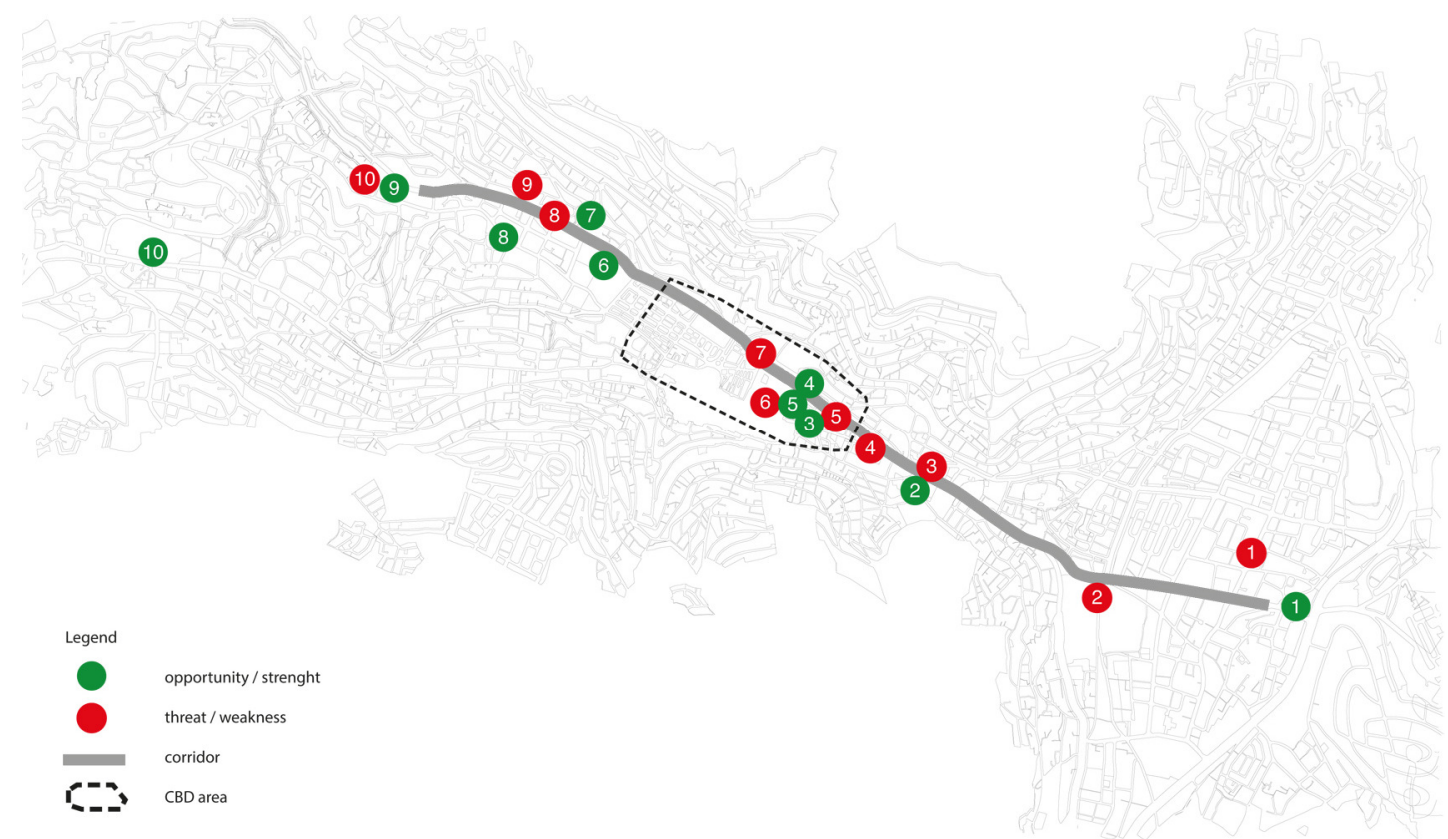

Fig. 5. TW-OS analysis along the main artery of the east-west corridor of Nablus 


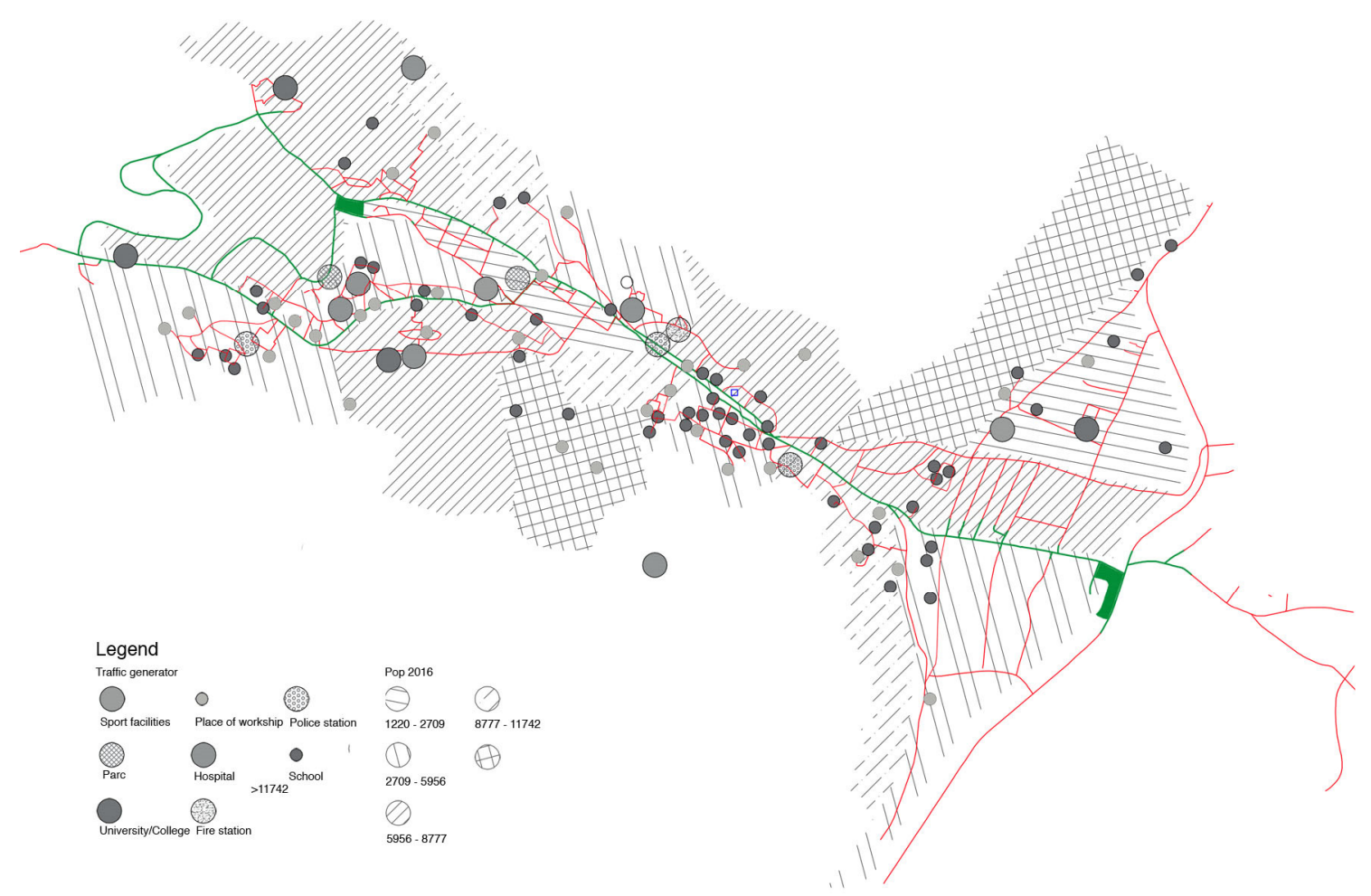

Fig. 6. Main flow generators along the east-west corridor of Nablus

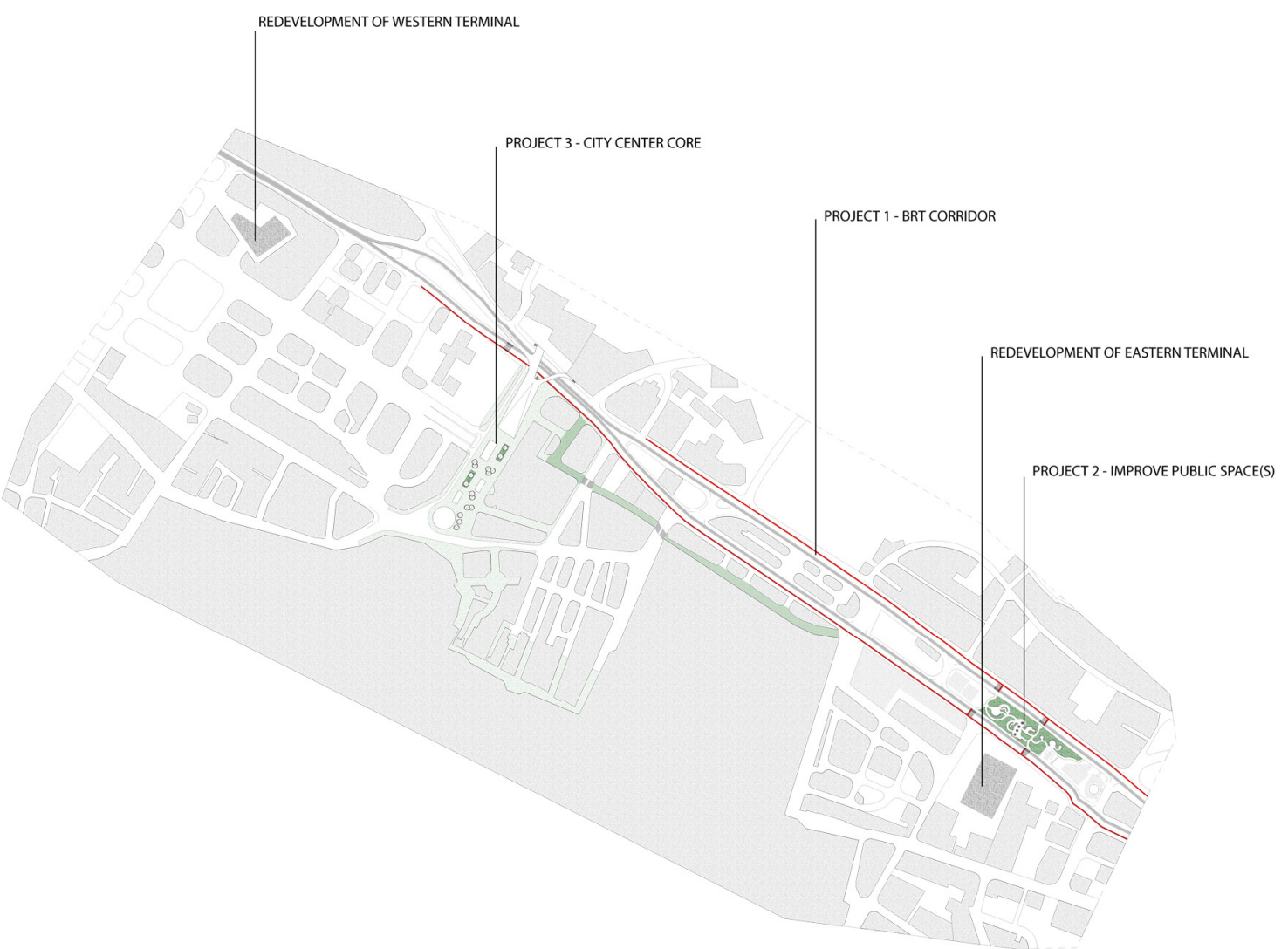

Fig. 7. Design proposal for the central area of Nablus 


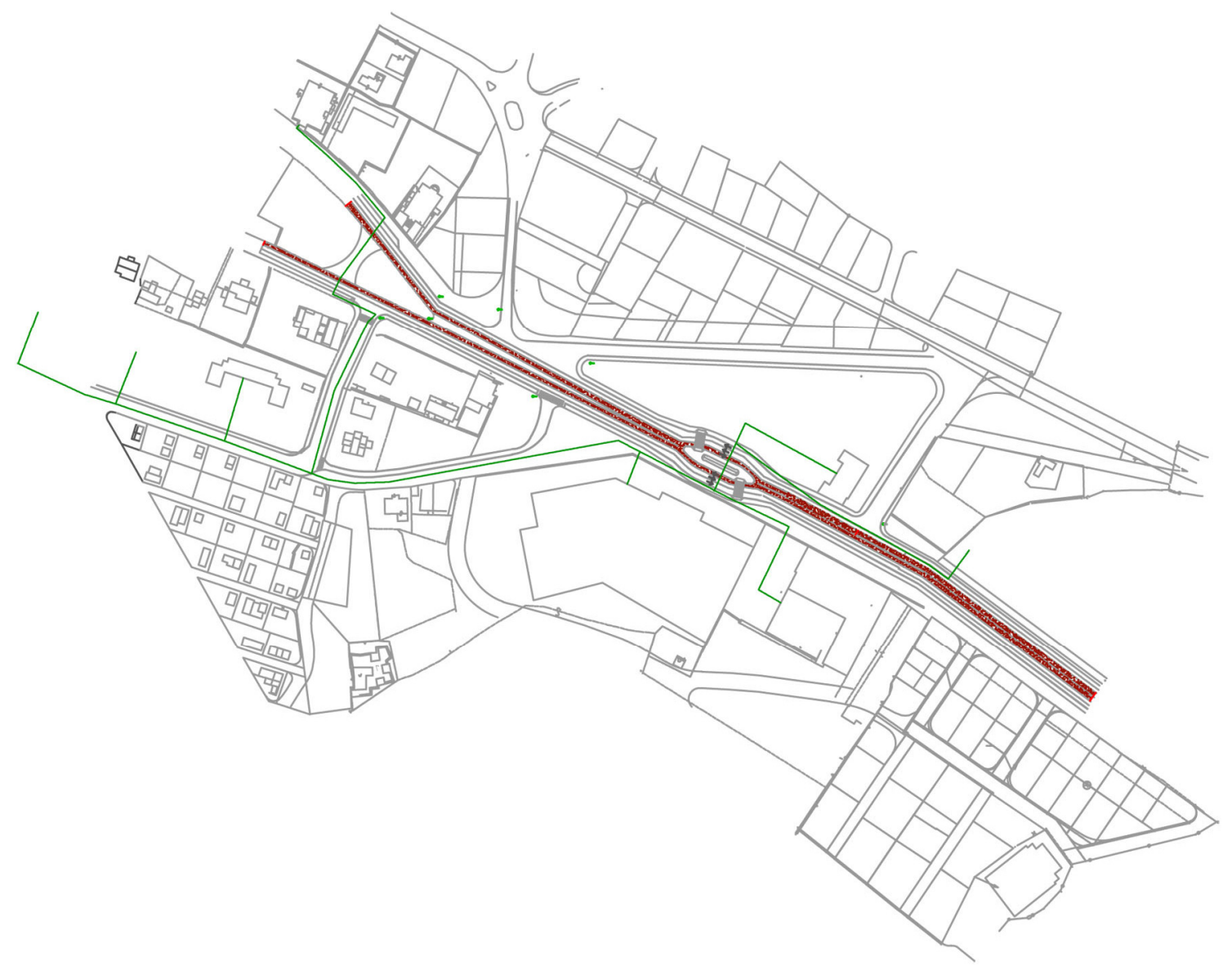

Fig. 8. Bus stop location and circulation scheme of the BRT system in Nablus 


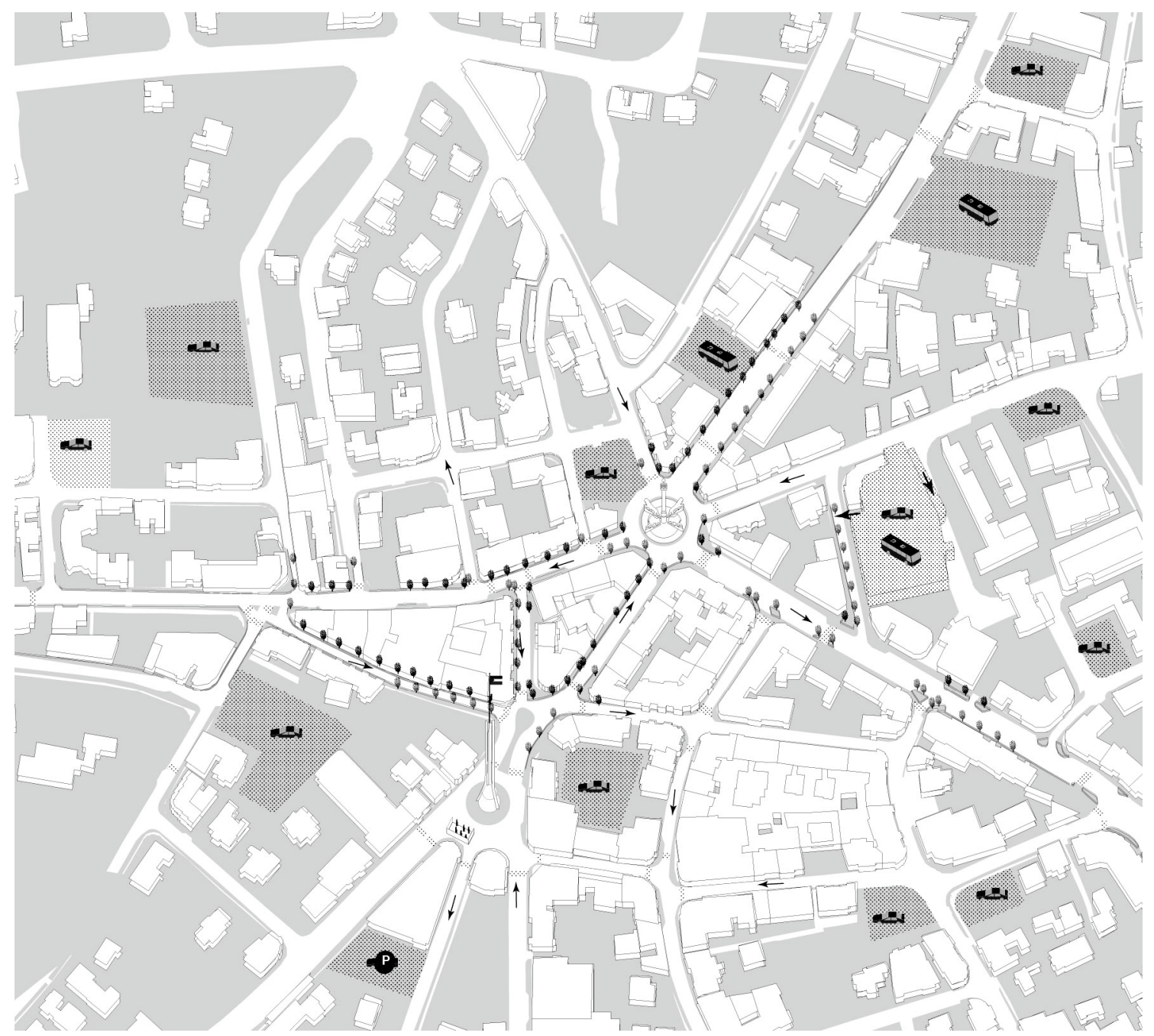

Fig. 9. Indication of central spaces used for car parking in Ramallah CBD 


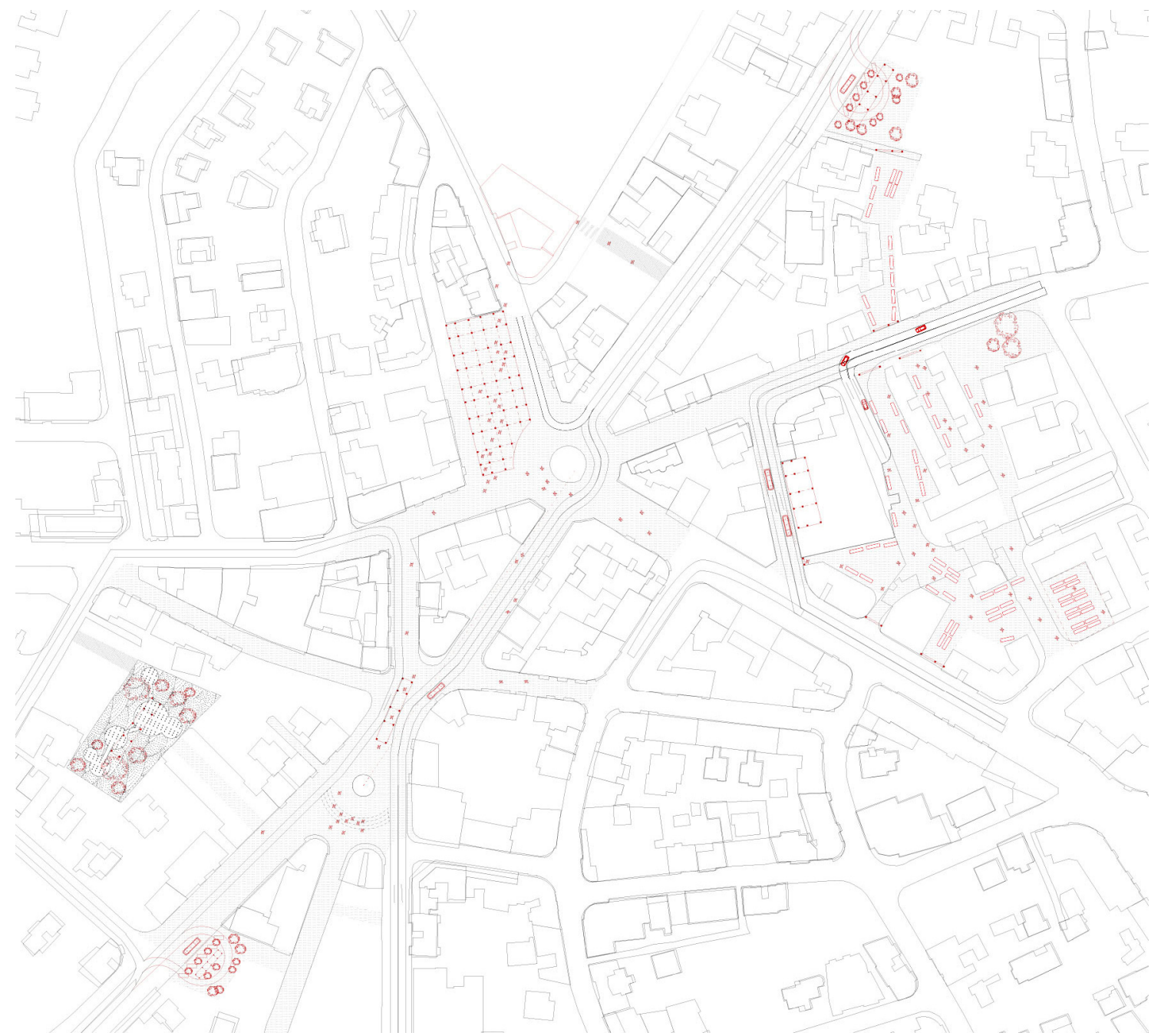

Fig. 10. Design proposal for a new system of public spaces for Ramallah city centre 


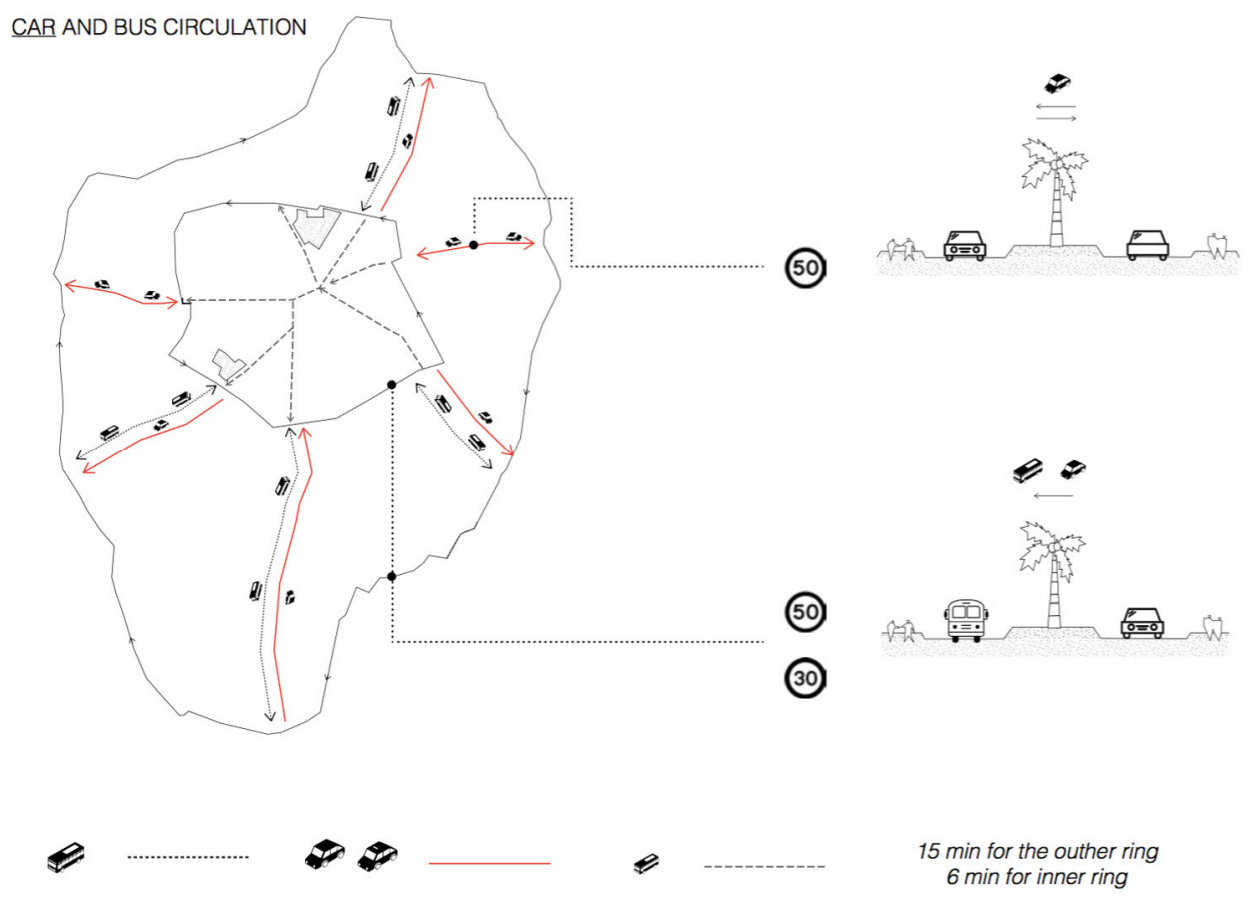

Fig. 11. Proposed car and bus circulation scheme for Ramallah

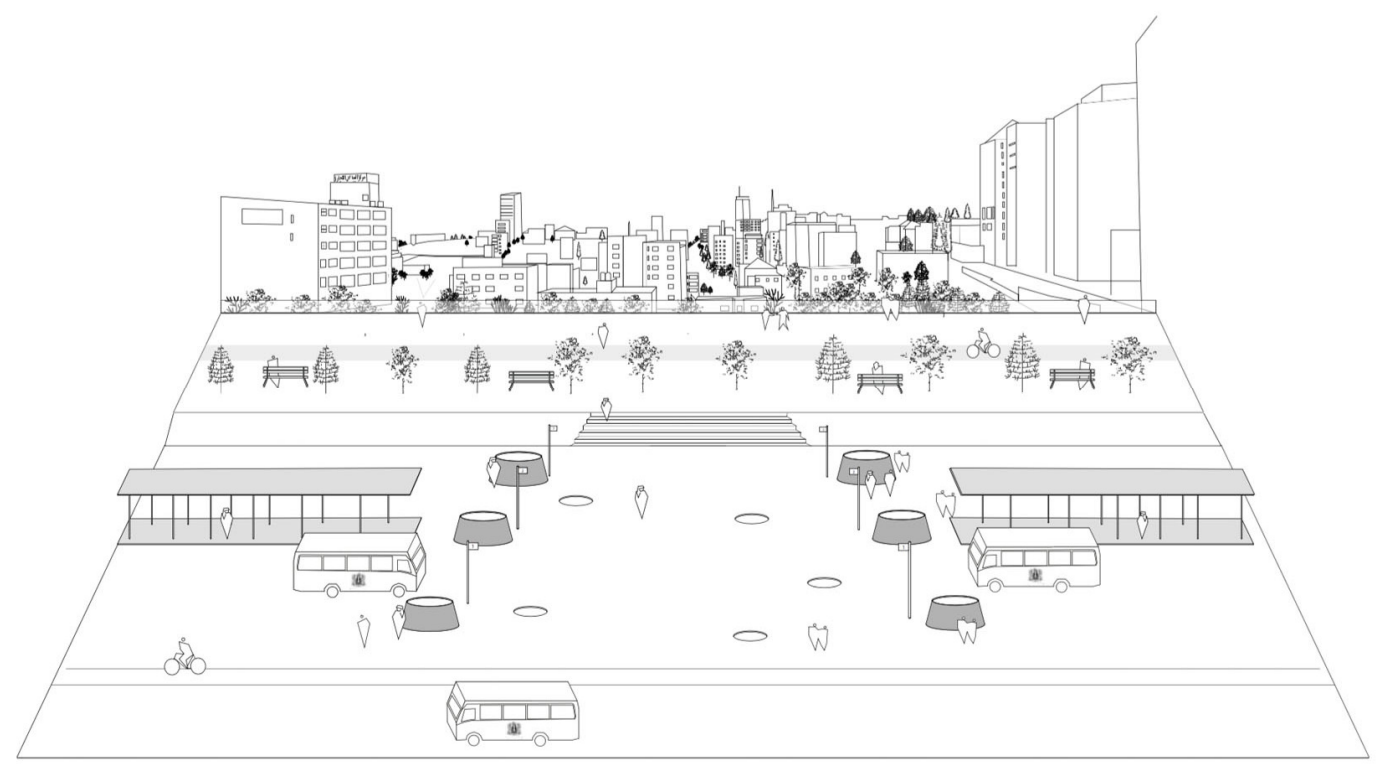

Fig. 12. View of the new belvedere bus terminal with underground parking 